\title{
TRESCIMO: European Union and South African Smart City Contextual Dimensions
}

\author{
Louis Coetzee, Andrew Smith \\ CSIR Meraka Institute, CSIR \\ Pretoria, South Africa \\ \{Louis.coetzee,Andrew.smith\}@csir.co.za
}

\author{
Alejandra Escobar Rubalcava, Andreea Ancuta Corici \\ Fraunhofer FOKUS \\ Berlin, Germany \\ \{alejandra.escobar.rubalcava/andreea.ancuta.corici\} \\ @)fokus.fraunhofer.de
}

\author{
Thomas Magedanz, Ronald Steinke \\ Technische Universität \\ Berlin, Germany \\ tm@cs.tu-berlin.de, ronald.steinke@tu-berlin.de \\ Marisa Catalan, Josep Paradells \\ i2CAT Foundation \\ Barcelona, Spain \\ \{marisa.catalan, josep.paradells\}@i2cat.net
}

\begin{abstract}
Cities increasingly face challenges related to pollution, efficient use of resources (e.g. water, energy) and ensuring a good quality of life for its citizens. Solutions built on existing and emerging technologies such as Cloud computing, Internet of Things, Machine-to-Machine and data analytics can improve on or create services able to address these challenges. These solutions are seen as contributors in creating a Smart City. In Europe Smart Cities have been implemented, while South Africa has only recently started with Smart City initiatives. Current thinking has been to replicate international Smart City instances in South Africa. However, an open question is raised if this is an optimal strategy as differences in context might impact on the delivery of services. This paper extracts and compares contextual differences between Europe and South Africa, and based on those insights analyse whether full European solutions will deliver on the promise of a South African Smart City. Furthermore the question is raised if insights into a South African Smart City can strengthen European initiatives. A need for inter-continental automated testing facilities such as those developed by TRESCIMO is identified through which integrated experiments can be conducted to provide insight and answers.

Index Terms-Smart City, Urbanization, Energy, Smart Grid, Water, Healthcare, Aging Population, Transportation, Automation, Road Infrastructure, School Dropout, Climate Change, Waste Management, Policies, Testbed, M2M.
\end{abstract}

\section{Introduction}

A good quality of life for city citizens, city sustainability, while reducing the negative effect on the environment are important aspects a city needs to address. Technological trends such as ubiquitous connectivity, smart data and analytics,

\author{
Hinesh Madhoo, Tiaan Willemse \\ Research, Testing \& Development \\ Group Sustainability Division, Eskom \\ Johannesburg, South Africa \\ \{hinesh.madhoo,WillemT\}@eskom.co.za
}

Joyce Mwangama, Nyasha Mukudu, Neco Ventura

University of Cape Town,

Rondebosch, South Africa

$\{$ joycebm, nyasha, neco\}@crg.ee.uct.ac.za
Maria Barros, Anastasius Gavras
Eurescom
Heidelberg, Germany
\{barros,gavras\}@eurescom.eu

Internet of Things (IoT), Machine-to-Machine (M2), and cloud computing create opportunities for new solutions for the challenges faced. Services for health-care, education, waste and sanitation, energy and water management, safety against hazards (floods and fire) food and personal safety can be implemented with the new technologies more rapidly and at lower cost then what was previously possible. They are seen as contributors in creating a Smart City. Figure 1 presents a view on a Smart City life cycle. Data is collected through sensors, communicated to back-end platforms, processed and stored with results and outcomes made available to society through services.

The European Commission defines the value of a Smart City as "...In Smart City, digital technologies translate into better public services for citizens, better use of resources and less impact on the environment..." [1].

Urbanisation is another global phenomenon and is adding to the challenges faced in cities [2]. According to [3] mass migration will result in more people living in cities than in the rural areas: “... by 2030 all developing regions, including Asia

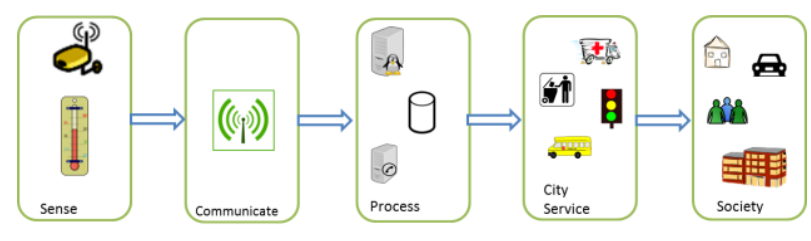

Figure 1: Smart City Life Cycle 
and Africa, will have more people living in urban than rural areas...". The African Union agenda for 2063 projects that

Africa is "to enter its urban age by 2063 when $50 \%$ of the population will live in urban areas, and reach nearly a quarter of the world's projected urban population" [4] .

While Smart Cities are becoming more prevalent in Europe, Asia and America, Smart Cities in Africa are still in its infancy. As stated in the African Union agenda for 2035 "Africa should not be left out in the creation of Smart Cities" [4].

This document captures differences and similarities between South Africa and Europe, specifically to understand how and what needs to be introduced, and what challenges need to be resolved to effectively create a South African Smart City and if possible how these solutions can also be incorporated into European initiatives. To obtain more detailed insight into a "future South African" Smart City and a European equivalent, dimensions related to application domains and governance are analysed in Sections II and III respectively.

Strengthening the study is the authors' track record in initiatives such as the European Technology Platforms' Future Internet Research and Experimentation Initiative (FIRE), the Future Internet and the $5 \mathrm{G}$ Programmes and on the South African side in a large initiative known as the Development Bank of South Africa smart and green fund (DBSA) aimed at establishing a "green" society. Authors in this paper are active in both the EU and South Africa, for example Prof. Dr. Thomas Magedanz, professor at Technical University of Berlin is an associated professor at University of Cape. Similarly, Dr. Louis Coetzee has collaborated with Fraunhofer FOKUS from early 2000 .

\section{Application Domains}

\section{A. Energy}

With a population of 52 million people, South Africa has a total generation capacity of about $40 \mathrm{GW}$ with an $82.7 \%$ electricity penetration. However, South Africa is in the midst of an energy crises impacting on its economy [5]. Furthermore, more than $90 \%$ of generation is done through coal-based facilities adding significantly to $\mathbf{C O}_{2}$ emissions [6].

South Africa recognizes that in order to attract new capital it is crucial to provide a reliable electricity service. Additionally, South Africa set a renewable energy target of $18.6 \mathrm{GW}$ by 2030 [7]. Nevertheless, coal's low price and local availability is making coal-based electricity more affordable in the short-term [8].

One of the main concerns of Europe is "Energy Security", since it has a large import dependency of energy resources. The dependency leads to power supply vulnerability due to international factors. Additionally, Europe has set three main targets for 2030: cut the greenhouse gas emissions, increase the share of renewable energy consumption and save energy [9].

One of the steps to achieve these goals is smart grid roll-out planned to be completed by 2020 , including replacing at least $80 \%$ of electricity meters with Smart Meters [10].

In both Europe and South Africa, similar requirements and approaches implying Smart Grid deployments are envisioned; however a challenge in the deployment of Smart Grids remains customer engagement. By knowing their power consumption, customers are able to decide whether to use energy or respond to price changes and consequently to decrease their electricity bill and GHG emissions [11].

\section{B. Water}

South Africa is a water-scarce country, thus amplifying the need for optimal water use. To react to particular challenges with regard to aging infrastructure, limited budgets for operations and maintenance and poor capabilities required for adequate water and sanitation, plans have been identified in [12]. Technical and non-technical (theft) [13] water losses have a significant impact on water availability. Maintaining clean water remains a priority as water pollution due to municipal pollution, effluent and acid mine drainage can impact on the drive for clean water.

Europe has abundant but unevenly distributed water resources [14]. In general, the quality of tap water is very high, following the "Drinking Water Directive" concerning the quality of the potable water quality [15]. The increasing urbanization and economic activities, such as agriculture, are over exploiting ground resources in Europe. Water scarcity is affecting $11 \%$ of the European population and $17 \%$ of European territory [16].

To overcome these challenges, Europe issued the objectives "of good ecological and chemical status for surface waters and good quantitative and chemical status for groundwater"[17]. Innovative collaborative solutions across public and private sector, non-governmental organizations are planned [18].

Water is a vital resource that must be managed carefully. Europe and South Africa face the challenge of overexploitation and scarcity. Europe and South Africa could beneficiate from the implementation of innovative technology to save and maintain clean water. Maintenance of current infrastructure and roll-out of new infrastructure have fallen behind from what is required for the South African population, creating an opportunity to leap-frog and immediately introduce smart technologies in new infrastructure roll-out.

\section{Health}

Access to health services are influenced by disparities in the South African health sector. A skills shortage related to healthcare professionals in both public and private sectors impacts on the cost, quality and availability of services [19]. $70 \%$ of the country's doctors serve $16 \%$ of the population via private sector health care. The remainder uses public healthcare [20]. Infant mortality rates varying significantly along racial and income lines support the challenge introduced through this disparity. South Africa has the largest anti-retroviral program in the world, but only $40 \%$ of eligible adults benefit from the program. This figure is alarming in a context where $17 \%$ of people with HIV/Aids live in South Africa [21]. The burden of disease is evident, but the challenges faced in the health care system impact on the ability to address it.

Europe enjoys a near-universal access to healthcare (97.7\%), high life expectancy and low infant mortality rates (3.9\%) [22]. Some of the key challenges of Europe are: 
Accelerated ageing population: people are living longer but the average age to which they enjoy good health remains the same [23]. Chronic diseases: cardiovascular, cancer, diabetes, mental illness, etc. represent $87 \%$ of all deaths [23]. Health inequalities: there is a vast difference between healthcare systems in member states. The life expectancy is influenced by factors such as employment, income, education and ethnicity and vary almost nine years between European countries [24]. Sustainability: Adapt to demographic changes and increasing demand for care while keeping costs in check. Health spending per capita since 2000 has increased more than two times faster than economic growth on average across OECD countries (4.0\% versus $1.6 \%)$ [25]. Currently, the health care sector is evolving by the using of ICT for early disease detection, monitoring and remote assistance.

Challenges identified between South Africa and Europe is quite different. While South Africa is pursuing a universal health care access and improving life expectancy, Europe is dealing with an ageing population and its economic impact onto the healthcare system. Nevertheless, South Africa and Europe need sustainable healthcare, where technology helps to improve population quality of life, maximizing resources and keeping costs to a minimum.

\section{Transport}

South African road infrastructure faces particular challenges. According to the South African National Development Plan [2] 69\% of all freight is transport by road. This strains already poorly maintained roads [26], which further impacts on road safety.

The cost of transport is high, which impacts on opportunities related to education, social and economic contribution [27]. Within cities commuter transport via minibus is largely unregulated and unsafe [28]. Initiatives are being implemented through Intelligent Transportation Systems to improve minibus efficiency in terms of time table planning and user recommendations [29].

The European transport policy, issued in 2014, aims to promote seamless transport chains for passenger and freight and close the gaps between member states transport networks [30]. Nevertheless, each country and cities, in particular, are establishing their own policies. For example, Germany created environmental zones where only "green cars" (low emission) are allowed to drive in the city centre [31]. Electric car usage is stimulated by making charging infrastructure available across Europe [32]. Moreover, Europe is incorporating full automation in their ports, e.g. Amsterdam harbour [33] going towards Internet of Things. Additionally, consumers increasingly adopting trends such as connected cars [34], and car sharing mobility on demand [35].

It is evident that the transport infrastructure in South Africa has not kept pace with the needs of the country. By following in Europe's footsteps and introducing appropriate policies and constraints (e.g. green areas in a city), pollution can be influenced, leading to a better citizen quality of life.

\section{E. Education}

The South African education is facing major challenges. This is especially true in terms of the tension between implementing changes that need both time and considerable resources to work their way through, and the close relationship of issues that need to be addressed at the sites of implementation i.e. in the schools, universities, and particularly, in the lives of human personnel. Basic education can generally be divided into private and public schools. The former, with qualified teachers, provides an effective environment; the latter is affected by lack of resources [36].

Societal factors also impact on the education pipeline. For example, the dropout rate is exceptionally high in schools, particularly for those pupils forced to care of parents and manage the household [37]. Similarly, senior schools charge fees and all schools require uniforms, which many cannot afford, thus reducing the opportunities for a broad education.

On average, European students spend 17 years in education [38]. The cost of teaching increases as the child moves through the education system, where the most important budget item is the expenditure on staff [39]. It is a challenge to Europe to increase or maintain the same levels of investment in education. Aging population and "brain" drain are impacting negatively on education [40]. On the other hand, virtual learning environments (VLE) presence is increasing rapidly in schools and universities [41]. In this sense, "Horizon Report Europe: 2014 Schools Edition" recognized two major trends: the role evolution of schoolteachers as the result of ICT and the influence of social media platforms, as a learning community [42]. As part of the objectives of the Strategic Framework for Education and Training 2020 (ET2020), the EU is working on policy development on Digital and Online Learning [43] to cooperate in the improvement of quality and efficiency of education and the promotion of equity and social cohesion [44].

The tertiary education systems in South Africa and Europe are trying to develop skills required to take advantage of the opportunities offered by disruptive technologies such as IoT by introducing IoT related courses and hands on laboratories at the postgraduate level [45]. The same approach is followed at South African universities, specifically at University of Capetown in the TRESCIMO project which contributes to transferring more knowledge to students.

\section{F. Natural Environment}

It has been noted that there is a link between the state of the environment and human health and well-being. According to the World Health Organisation, an estimated 23\% of all deaths in Africa are a result of avoidable environmental hazards such as contaminated water, poor hygiene, inadequate sanitation, poor water resource management, use of unsafe fuels, atmospheric pollution and poor infrastructure [46]. Specific to South Africa, this is estimated at $16 \%$ of all deaths.

Waste Management is a factor influencing the broader health and quality of life for citizens. There are efforts to enforce regular waste reporting and monitoring, as yet not fully implemented. A recent report showed the national waste baseline of South Africa generated approximately 108 million 
tonnes of waste in 2011, of which 98 million tonnes were disposed of in landfills. Due to the complexity of waste management, only about $10 \%$ of all waste generated in South Africa was recycled in 2011 [47].

European municipalities and citizens are realizing that environmental damages will have a negative impact on their present and future well-being. Thus, as stated by the European Environmental agency [48] in the last years notable effort has been made to reduce air pollution. However, this is still responsible for more than 400 thousand premature deaths in Europe each year. As an insight of the economic impact of pollution harm, in [49] the damage caused only by industrial facilities emissions was estimated to be of at least 102-169 billions of Euros. To address this problem, Europe established directives and measures devoted to regulate and minimize the levels of pollution. Thus, at local level some actions and effort need to be taken in order to keep reducing the main sources of pollution (industrial, households, vehicle emissions) and also to supervise that healthy air quality levels are reached and maintained [48].

Both for South Africa and Europe, natural environment is an area where IoT solutions can improve the ecosystem by monitoring and analysis to discover factors contributing to poor health and improve the efficiency of waste management.

\section{Governance and Policy}

The introduction of the Protection of Personal Information Act of South Africa will have a significant impact on the creation and exploitation of information, especially linked to an individual. A key aspect of the act is the requirement that an individual must consent to have his information shared and stored [50].

SA faces significant challenges related to corruption and good governance [51] [52]. This aspect impacts on South Africa's ability to effectively roll-out disruptive programs addressing aspects described earlier.

The European Commission launched the program "EU Smart Cities and Communities" (SCC). One of the action clusters is the Policy \& Regulations action cluster [53]. Its aim is to set the policies and regulations needed to enable largescale implementation and roll-out of Smart Cities [54], e.g. governing models, engagement plans and monitoring activities.

In contrast, South Africa has not set policies related to Smart Cities. An important one which will affect any Smart City roll-out is that of protecting personal information.

\section{Remarks and Analysis}

The perceived benefits from applying Smart City concepts in both South Africa and Europe are evident. Aspects such as water and energy security are critical for both.

Viewing the above, the similarities are evident, but the drivers differ. For instance, in Europe, the population is aging, while South Africa has an increase in birth-rates. Connectivity in South Africa remains expensive and limited to a relatively small part of society, in contrast to Europe where there is $97 \%$ fixed broadband coverage [55].
To leverage benefits from smart services in domains such as transport, energy, water etc. challenges faced need to be addressed. Viewing services holistically, the trade-off between the ease of implementation vs. the potential for impact is important both for Europe and South Africa. Smart services have the potential to make impact, but their introduction is hampered by the context in which they are planned for.

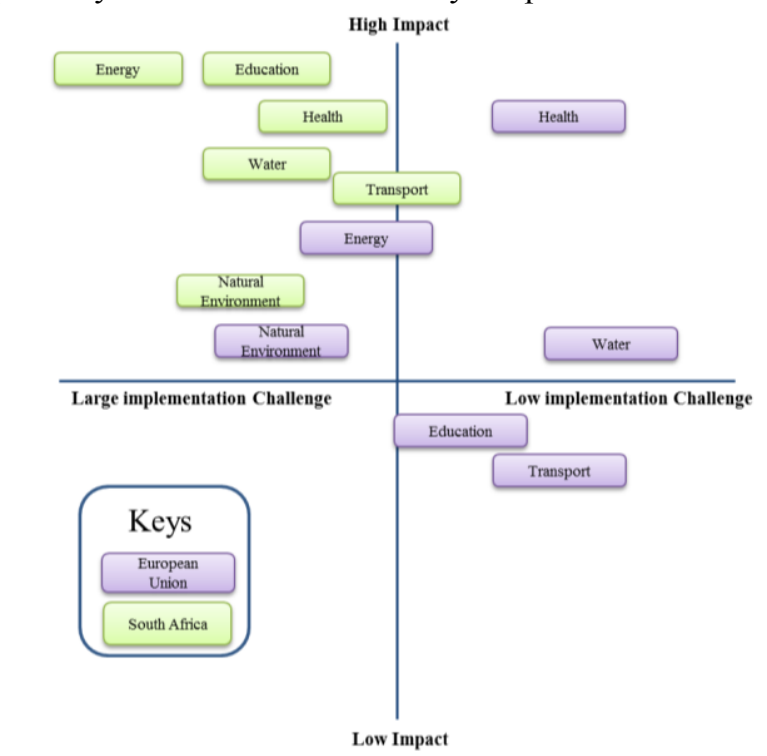

Figure 2 Smart City Service implementation vs impact framework

Figure 2 depicts a subjective framework highlighting where Smart City services can have the highest impact and how difficult it will be to roll-out. It is assumed that a service will have a "lower" impact if there is already a "working" solution. For instance, energy in South Africa is a challenge and is affecting the economy. It is difficult to introduce mechanisms to improve energy stability. Contrasting, energy is mostly stable in Europe, thus introducing mechanisms such as demand side management will have some impact, but not to the extent as in South Africa. Similarly, there are fewer barriers to roll-out these types of solutions.

Generally, Europe faces lower barriers to entry for smart services than South Africa. Services impact is mostly high in both areas. The mostly stable infrastructure in Europe implies that the need is not as high (except from a green perspective) compared to South Africa where the service itself must cater for the fact that the infrastructure are not at a desirable level.

\section{TRESCIMO's Potential Impact}

By breaking down various domains as presented earlier challenges are highlighted. It is evident that a "big bang" solution will most likely not have the desired effect. It is also evident that experiments will be required, spanning continents with different challenges. TRESCIMO- Testbeds for Reliable Smart City Machine to Machine Communication is one such initiative where experimental facilities specifically aimed at creating frameworks allowing for design and implementation of services that can be universal [56]. The concept is depicted in Figure 3. Through its federated, inter-continental research infrastructure TRESCIMO is conducting Smart City Service 


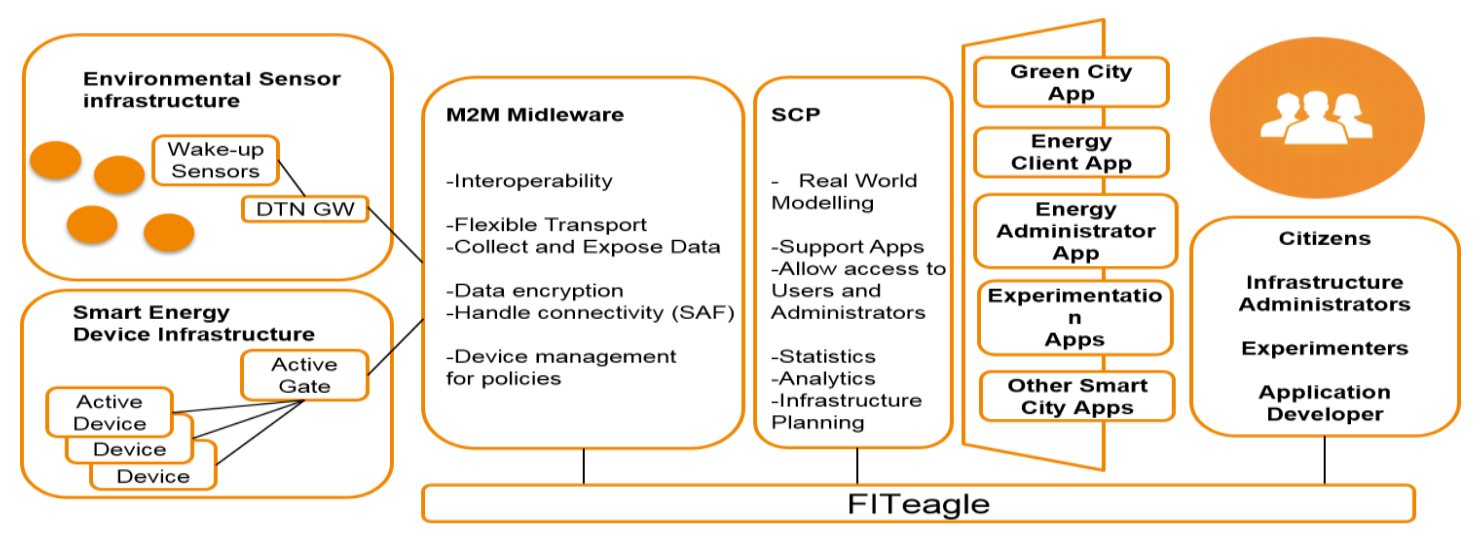

Figure 3 TRESCIMO Components

experiments with energy and the natural environment as domains. In addition to the identification and implementation of suitable infrastructure, TRESCIMO is analysing effects such as user acceptance of smart infrastructures in homes, utilising minimal connectivity infrastructure in environmental monitoring and at the same time maximize the potential of a federation of data centres. Two trials and a Proof-of-Concept are envisioned in TRESCIMO: In Europe an environmental trial is implemented testing a solution that can be deployed quickly using Delay Tolerant Networks (DTN). In South Africa a demand-side energy trial is implemented.

The Proof-of-Concept takes advantage of the testbed federation (Figure 4) built on top of three data centres located at the University of Cape Town, Technical University of Berlin, and CSIR Pretoria. Concepts of programmable network and devices are developed to have the Network Functions (NF) OpenMTC M2M Server and the Smart City Platform IoT engine deployed on demand on the three data centres to enable connectivity experiments using OpenSDNCore [57] as NFV orchestrator and FITeagle [58] as semantic FIRE (Future Internet Research and Experimentation) middleware. DTN components located at I2CAT Barcelona and smart meters located at CSIR Pretoria are enhanced to adapt to the network function placement actions by programmatically changing the endpoint to send data to, using the Lightweight M2M device management protocol. The aim of this activity is to be able to easily carry out experiments regarding the location of the NFs in order to understand how energy load-shedding could be tackled by programmable device and network elements in South Africa. The results of the experiments will reveal statistics on the best location to place the functions depending on the source of the data to collect and load-shedding timetable.

\section{Conclusions}

Smart City concepts as means to address challenges faced in cities have risen to prominence. The benefit, drivers and means to implement those services are clear in a European context. In

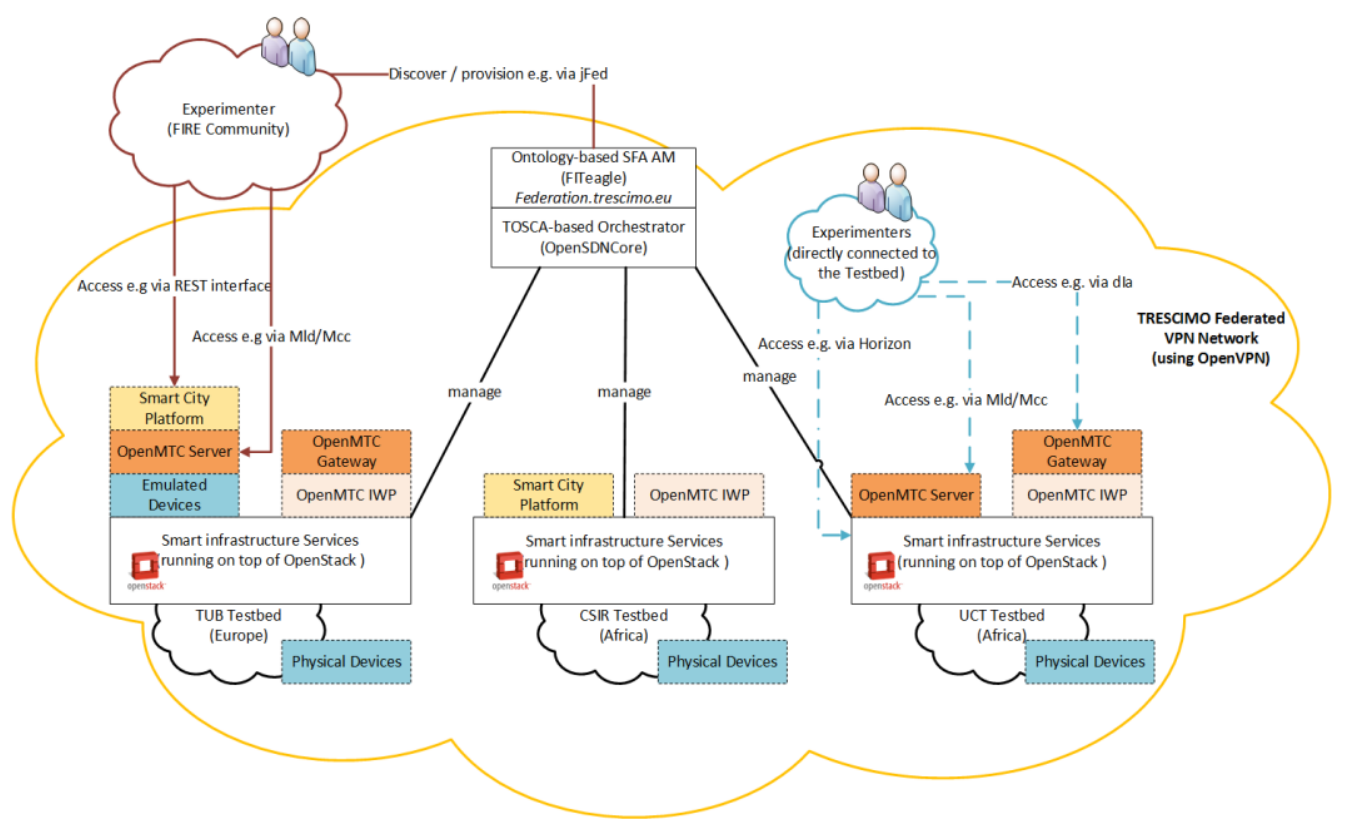

Figure 4: TRESCIMO Federated Testbed 
a South African context there are open questions as to how a South African Smart City would look.

This paper has analysed aspects where the context differs. Subjectively contrasting "ease of implementation" with "potential for impact", services are evaluated. In both environments services will deliver on their impact promise, with ease of deployment more challenging in South Africa. The ease of implementation highlights two important aspects 1) South Africa can learn from Europe as to how to implement these services and 2) it is not guaranteed that a European service will be rolled out seamlessly as a typical service has to cater for many more and different factors.

This aspect creates a bi-directional opportunity. South Africa can benefit from the prior learnings and implementations to improve aspects related to service delivery and resource management, even though the fundamental drivers and how the service contributes to a solution are different. Similarly, Europe can gain from the knowledge of how to generalize a typical service to cater for more aspects than what the context expects. Finding ways to introduce services in an environment with more constraints (e.g. policy, infrastructure etc.) will also improve the value of a service. Viewing the challenges described (both size and diversity) a testbed environment is required to move from lab into a scaled environment. TRESCIMO is one such environment where research facilities spanning continents are created. The vision of TRESCIMO is to demonstrate social impact through applications and demonstrations of Smart City services in both Europe and South Africa.

\section{References}

[1] European Commission, "Smart Cities." Available online. https://ec.europa.eu/digital-agenda/en/smart-cities

[2] National Planning Commission, "National Development Plan 2030: Our Future-make it work." Available online. http://www.statssa.gov.za/wp-content/uploads/2013/07/NDP2030-Our-future-make-it-work.pdf

[3] UN-HABITAT, "Cities for All: Bridging the Urban Divide State of the World Cities 2010/2011," no. 004/14E. 2011 Available online. http://unhabitat.org/books/state-of-theworlds-cities-20102011-cities-for-all-bridging-the-urbandivide/

[4] The African Union Commission, "AGENDA 2063 - The Africa We Want." May-2014 Available online. http:/www.nepad.org/system/files/Agenda $\% 202063 \% 20 \% 20$ English.pdf

[5] SAnews.gov.za, "President unveils bold plan to tackle energy crisis." 2015 Available online. http://www.sanews.gov.za/south-africa/president-unveilsbold-plan-tackle-energy-crisis

[6] Greenpeace, "True Cost of Coal - Greenpeace." Oct-2011 Available online. http://www.greenpeace.org/africa/Global/africa/publications/c oal/TrueCostOfCoal.pdf

[7] South African Government Department of Energy, "Renewable Energy." Available online. http://www.energy.gov.za/files/renewables_frame.html

[8] R. Priddle, “Africa Energy Outlook." International Energy Agency, $2014 \quad$ Available online. http://www.iea.org/publications/freepublications/publication/ africa-energy-outlook.html

[9] European Commission, "2030 Energy Strategy." Available online. http://ec.europa.eu/energy/en/topics/energystrategy/2030-energy-strategy

[10] European Commission, "Smart Grids and Meters." Energy Available

https:/ec.europa.eu/energy/en/topics/markets-and-

consumers/smart-grids-and-meters

[11] European Task Force For The Implementation Of Smart Grids Into The European Internal Market, "Mission and Work Program." 2012 Available online. https://ec.europa.eu/energy/sites/ener/files/documents/mission and_workprogramme.pdf

[12] South African Goverment Department of Water and Sanitation, "Ageing infrastructure and other water challenges will be problems of the past DWS." Available online. https://www.dwaf.gov.za/stories/Ageing\%20infrastructure $\% 2$ 0article.pdf

[13] M. Matshediso, "Vandalism, theft deny citizens access to water." South African Government News Agency, Sep-2014 Available online. http://www.sanews.gov.za/southafrica/vandalism-theft-deny-citizens-access-water

[14] EEA, "EU Precipitation Geographic coverage," 2011 Available

http://www.eea.europa.eu/themes/water/waterresources/figures-and-maps/precipitation/view

[15] Council of the European Union, "Council Directive 98/83/EC of 3 November 1998 on the quality of water intended for human consumption," Official Journal of the European Communities, Nov. 1998.

[16] EEA, "Water resources across Europe confronting water scarcity and drought," EEA Report, vol. 2, 2009.

[17] European Commission, "The EU Water Framework Directive," 2014.

[18] EIP, "European Innovation Partnerships - Online Market Place," 2015 Available online. http://www.eip-water.eu/about

[19] Agility Global Health Solutions, "Private Healthcare set to face tough challenges in 2013." Dec-2013 Available online. http://www.moneyweb.co.za/archive/private-healthcare-setto-face-tough-challenges-in/

[20] Africa Health Placements, "The Need: No people = no healthcare." Available online. http://www.ahp.org.za/nopeople-no-healthcare

[21] S. Benatar, "The challenges of health disparities in South Africa," The South African Medical Journal, vol. 103, no. 3, 2013.

[22] Eurostat, "Quality of life indicators - health," Oct. 2013 Available online. http://ec.europa.eu/eurostat/statisticsexplained/index.php/Quality_of_life_indicators_health\#Access to healthcare provision

[23] European Commission, "Public Health," Nov. 2014.

[24] Eurostat, "Mortality and life expectancy statistics," Jun. 2015 Available online. http://ec.europa.eu/eurostat/statisticsexplained/index.php/Mortality_and_life_expectancy_statistics

[25] OECD, "Health at a Glance 2011 OECD Indicators," Nov. 2011.

[26] Earthworks, "The state of South Africa public transport system." 2015 Available online. http://www.afrisam.co.za/news/afrisam-industrycommentary/2014/10/the-state-of-south-africa $\%$ E2\%80\%99spublic-transport-system/the-state-of-southafrica $\% \mathrm{E} 2 \% 80 \% 99$ s-public-transport-system/ 
[27] South African Government, SA Yearbook 2013/14. Government of South Africa, 2014 Available online. http://www.gov.za/about-sa/transport

[28] K. Lucas, "Making the connections between transport disadvantage and the social exclusion of low income populations in the Tshwane Region of South Africa," Journal of Transport Geography, vol. 19, no. 6, pp. 1320-1334, 2011 Available online. http://eprints.whiterose.ac.uk/79117/8/Lucas\%202011\%20aut hor\%20final\%20draft.doc

[29] Gauteng Province: Roads and T. R. of South Africa, "Gauteng on the move." Nov-2013 Available online. http://www.itmp25.gpg.gov.za/documents/Annex-KIntelligent-Transport-Systems-Nov13.pdf

[30] European Commission, "Connecting Europe What do we want to achieve?" Available online. http://ec.europa.eu/transport/themes/infrastructure/index_en.h tml

[31] M. Kroenert, "Umweltplakette/Feinstaubplakette Informationen und Bestellm." Available online. https://www.umwelt-plakette.de/

[32] Amsterdam Roundtables Foundation, "Evolution - Electric vehicles in Europe: gearing up for a new phase?" Apr-2014 Available online. http://www.mckinsey.com//media/mckinsey\%20offices/neth erlands/latest $\% 20$ thinking/pdfs/electric-vehicle-reporten_as\%20final.ashx

[33] R. van den Berg, "Data sharing and IT as key elements for the future growth." Nov-2014 Available online. http://www.intermodal-events.com/files/roy_vd_berg.pdf

[34] UK Government Chief Scientific Adviser, "The Internet of Things: making the most of the Second Digital Revolution." Dec-2014 Available online. https://www.gov.uk/government/uploads/system/uploads/atta chment_data/file/409774/14-1230-internet-of-thingsreview.pdf

[35] N. Gibbs, "Car2Go poised to top 1-million users." Nov-2014 Available online. http://europe.autonews.com/article/20141113/ANE/14111992 3/car2go-poised-to-top-1-million-users

[36] Van der S. Burger C. Burger R. de Vos M. du Rand G. Gustafsson M. Shepherd D. Spaull N. Taylor S. van Broekhuizen H. Berg and D. von Fintel, "Low quality education as a poverty trap," Stellenbosch: University of Stellenbosch, Department of Economics. Research report for the PSPPD project for Presidency., 2011.

[37] N. Branson, C. Hofmeyr, and D. Lam, "Progress through school and the determinants of school dropout in South Africa," Development Southern Africa, vol. 31, no. 1, pp. 106-126, 2014.

[38] Eurostat, "Education statistics," Jul. 2011 Available online. http://ec.europa.eu/eurostat/statistics-

explained/index.php/Education_statistics

[39] Eurostat, "Educational expenditure statistics," Jun. 2015 Available online. http://ec.europa.eu/eurostat/statisticsexplained/index.php/Educational_expenditure_statistics

[40] A. Aslund, "Southern Europe Problem: Poor Education." May-2013 Available online. http://blogs.piie.com/realtime/?p=3563

[41] European_Commission, "Survey of Schools: ICT in Education," Digital Agenda for Europe, 2013 Available online. https://ec.europa.eu/digital-agenda/sites/digitalagenda/files/KK-31-13-401-EN-N.pdf
[42] European Commission, "Horizon Report Europe 2014 Schools Edition," Horizon Report Europe, 2014 Available online. https://ec.europa.eu/jrc/sites/default/files/2014-nmchorizon-report-eu-en_online.pdf

[43] Eurpean_Commision, "WG on Digital and Online Learning," 2014 Available online.

http://ec.europa.eu/education/policy/strategic-

framework/expert-groups/documents/wg-digitalmandate_en.pdf

[44] European Commission, "Strategic framework Education \& Training 2020," 2015 Available online. http://ec.europa.eu/education/policy/strategicframework/index en.htm

[45] N. Branson, C. Hofmeyr, and D. Lam, Progress through school and the determinants of school dropout in South Africa. A Southern Africa Labour and Development Research Unit Working Paper Number 100. Cape Town: SALDRU, University of Cape Town, 2013.

[46] C. Wright and L. Godfrey, "The impact of an unhealthy environment on human health in South Africa," CSIR, 2010 Available online. http://www.csir.co.za/nre/docs/Briefing\%20Note\%20No4\%2 02010_environmental\%20health_FINAL.pdf

[47] "National Waste Information Baseline Report," South African Waste Information Centre (SAWIC), 2012 Available online. http://sawic.environment.gov.za/documents/1880.pdf

[48] "Urban adaptation to climate change in Europe Challenges and opportunities for cities together with supportive national and European policies," European Environment Agency, 2012.

[49] "Revealing the costs of air pollution from industrial facilities in Europe," European Environment Agency (EEA)Technical report, 2011 Available online. http://www.eea.europa.eu/publications/cost-of-air-pollution

[50] South Africa Department of Justice and C. Development, "The Protection of Personal Information Act (POPI)." Nov2013 Available online. http://www.justice.gov.za/legislation/acts/2013-004.pdf

[51] Republic of South Africa, "Fraud and Corruption Prevention." 2015 Available online. http://www.tourism.gov.za/AboutNDT/Branches1/Administra tion/Pages/Corruption-and-Fraud.aspx

[52] South African Government, "We can all help to stop corruption." $2014 \quad$ Available online. http://www.gov.za/blog/we-can-all-help-stop-corruption

[53] SCC, "Action Clusters," Market Place of the European Innovation Partnership on Smart Cities and Communities, 2014 Available online. https://eu-smartcities.eu/actionclusters

[54] SCC, "Policy \& Regulations / Integrated Planning," Market Place of the European Innovation Partnership on Smart Cities and Communities, 2014 Available online. https://eusmartcities.eu/policy-regulations-integrated-planning

[55] EENEE and N. networks of experts, "European Education and Training Systems in the Second Decennium of the Lisbon Strategy." Jun-2008 Available online. http://www.nesetweb.eu/sites/default/files/challenges-ofeuropean-education.pdf

[56] "TRESCIMO - Testbeds for Reliable Smart City Machine to Machine Communication." Available online. http://trescimo.eu

[57] OpenSDNCore, www.opensdncore.org

[58] FITeagle, fiteagle.org 